\title{
MORBIDITY AND MORTALITY IN PATIENTS 70 YEARS OF AGE AND OVER UNDERGOING ISOLATED CORONARY ARTERY BYPASS SURGERY
}

\author{
Pavel Žáček, Jan Dominik, Jan Harrer, Vladimír Lonský, Jiř́ Mandák, Pavel Kuneš, Miroslav Solar̆
}

University Teaching Hospital in Hradec Králové: Department of Cardiac Surgery

\begin{abstract}
Summary: Background and aim: Due to the constantly improving results of surgical revascularization for coronary heart disease even the elderly patients are offered more frequently this type of treatment. Since older age is a harbinger of reduced vital capacity and increased morbidity the results of coronary artery bypass grafting (CABG) in elderly as well as long-term benefit deserve a careful examination. Materials and methods: 1475 isolated CABG procedures performed between 1995 and 1997 in a university hospital cardiac surgery unit, divided in group I (age below 70, $n=1324$ ) and group II (age 70 and over, $n=151$ ). A retrospective analysis of pre-operative, peri-operative and post-operative data. Results: Significant differences (lower BMI and BSA, advanced NYHA and CCS stage, higher prevalence of diabetes, renal dysfunction and extracardial atherosclerotic lesions) were found in elderly. CABG was performed in both groups with no differences in technique of procedure (only slightly longer duration of CPB in group II). However, there was markedly higher mortality ( 2.3 vs. $7.3 \%, p<0.005)$, incidence of NearMiss $+(18.4$ vs. $36.4 \%$, p < 0.005$)$ and post-operative morbidity $(34.6$ vs. $56.3 \%, \mathrm{p}<0.005)$ in the older group, which was also expressed in a longer ICU stay and postoperative hospitalization. Conclusion: Coronary revascularization can be performed in elderly with higher but still acceptable risk. Higher mortality and associated morbidity is caused by higher preoperative prevalence of known risk factors as well as generally reduced vital capacity. Surgical procedure should not be denied to elderly population because of the age alone but a careful evaluation of an individual patient is required.
\end{abstract}

Key words: Coronary disease; Coronary surgery; Bypass; Elderly; Risk factors; Mortality

\section{Introduction}

Coronary revascularization for ischaemic heart disease is a well established method capable of effective relief of symptoms of ischaemia and improving the long-term prognosis of the patients. Due to the excellent results the surgical procedure is continuously being offered to the older population (Fig. 1). Though yielding similar benefits the surgical revascularization in elderly is accompanied by higher incremental risks caused by age-related morbidity and probably a globally reduced vital capacity.

\section{Materials and Methods}

A total of 1584 coronary revascularization procedures were performed at our cardiac surgery unit in years 1995 1997. From this cohort 1475 patients in whom CABG was performed as an isolated procedure were enrolled in the study. These patients were divided in two groups: I - the patients of the age below 70, and II - the patients of the age 70 and older.

A complete set of preoperative, operative and postoperative data were analysed. The data were retrieved from the
Patient Analysis Tracking System Database provided by Medicon CZ and completed from the patients medical documentation. The paired values for groups I and II were compared using two sample T-test and chi-square test for contingency tables. A statistically significant difference was accepted at a $\mathrm{p}$ value $=0.05$.

\section{Results}

Three categories of parameters were analysed containing 1) the demographic preoperative data, 2) the data characterizing the surgical procedure and 3) postoperative course.

There were significant differences found between group I and II in all three data categories.

In demographic data there were significant differences both in BMI (27.5 v.s. 26.4, p (0.001) and BSA (1.94 vs. $1.86, \mathrm{p} \leq 0.001)$. The prevalence of diabetes was higher among the elderly ( 27.4 vs. $41.7 \%, \mathrm{p} \leq 0.005)$. There were significant differences in frequency of haemodynamically important carotid lesions ( 23.6 vs. $31.1 \%$, p $\leq 0.05)$ and obliterative arteriosclerosis of peripheral vessels (14.2 vs. $20.5 \%, p \leq 0.05)$. The renal dysfunction was present in $19 \%$ 


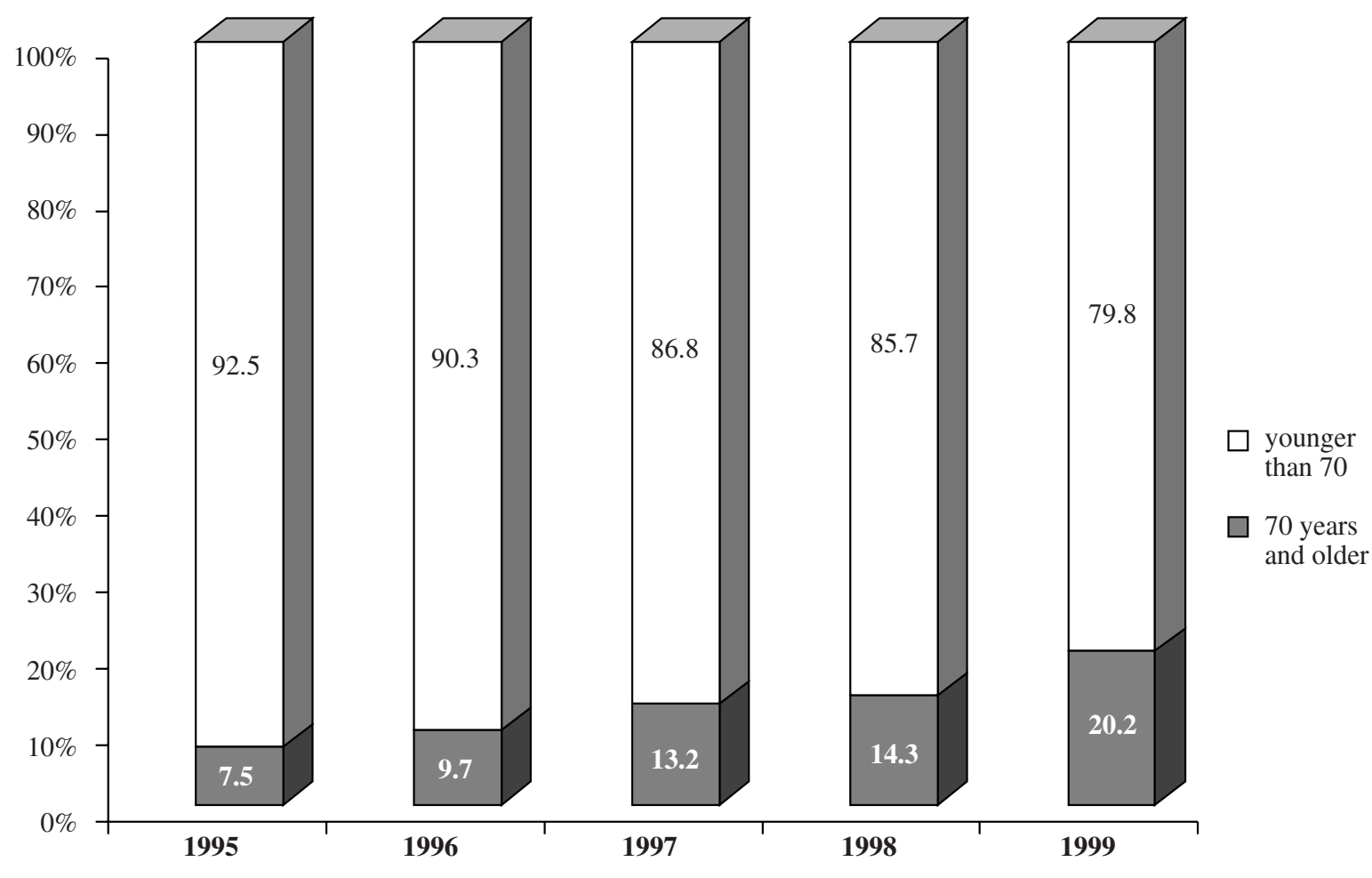

Fig. 1: Increasing proportion of elderly patients in coronary bypass surgery in KCH-HK unit.

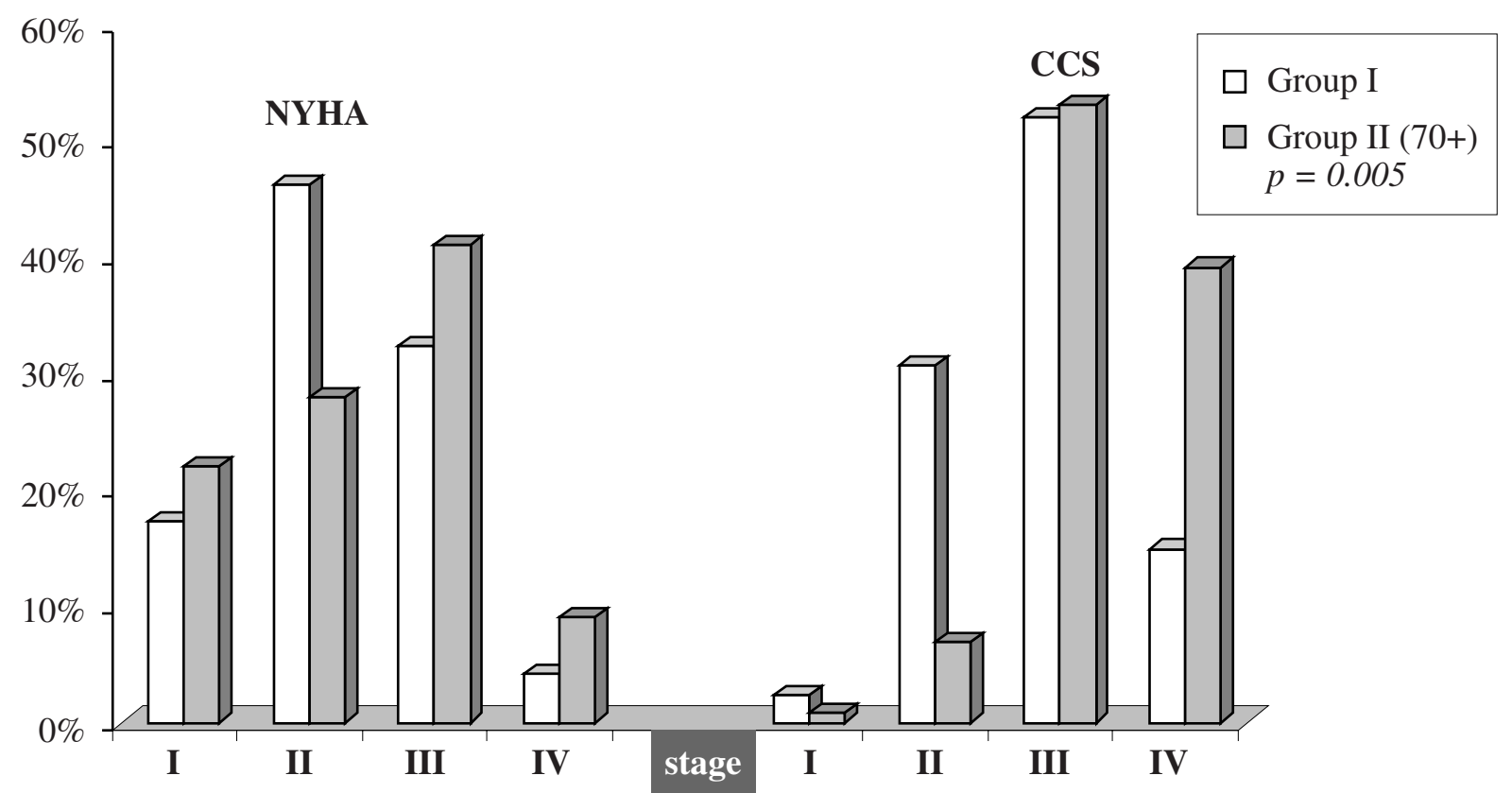

Fig. 2: The elderly CABG patients are operated at the advanced stages of the heart disease according to NYHA and CCS classification. 
of elderly patients compared to $10.8 \%$ in the younger group, and the preoperative serum creatinine level in elderly was higher respectively ( $90.5 \mathrm{vs} .99 .1 \mu \mathrm{mol} / 1, \mathrm{p} \leq 0.006)$. A markedly different distribution in NYHA (dyspnoea) and CCS (angina) classification was present (Fig. 2) with pronounced shift towards higher stages in both classifications. Interestingly, the prevalence of current smokers was lower in elderly ( 21.2 vs. $8.6 \%, p \leq 0.005)$. On the contrary, the differences in hypercholesterolaemia, hypertension, history of TIA or stroke, previous myocardial infarction, cardiological or cardiosurgical interventions and ejection fraction were not found significant (Tab. 1).

The revascularization procedure was performed as elective in $62 \%$ of the younger patients while only in $38 \%$ of the elderly (non-elective procedure being defined as any other than ruled by the waiting list: the urgent transfer from the catheterization room or CABG performed because of severe/unstable angina, postinfarction angina or presence of critical coronary lesions within the same hospitalization). The length of cardiopulmonary bypass, aortic cross-clamp, number of distal anastomoses, total blood loss, length of intubation and the use of intra-aortic balloon pumping were examined but with exception of longer extracorporeal circulation in older group ( 73.8 vs. $81.3 \mathrm{~min}, \mathrm{p} \leq 0.05)$ no other significant differences were found (Tab. 2).

The 30-days mortality of the whole cohort of isolated CABG was $2.9 \%$, but it was markedly different between the younger and the elderly (2.3 vs. $7.3 \%$, p $\leq 0.005)$. Similarly, the incidence of NearMiss + which is defined as occurrence of one or more major complications almost leading to death of the patient was significantly higher in the older group ( 18.4 vs. $36.4 \%, \mathrm{p} \leq 0.005)$. The incidence of postoperative complications in elderly was higher both globally ( 34.6 vs. $56.3 \%, p \leq 0.005)$ and in all analysed types of complications. Renal and respiratory failure, neurological and neuropsychological disorders, arrhytmias and low cardiac output were the complications strikingly more pronounced in the elderly group. The older patients required more transfusions of autologous blood ( 2.2 vs. 3.3 transfusion units, $p=0.001$ ) and stayed longer at ICU (56.3 vs. 66.0 hours, $\mathrm{p} \leq 0.04)$. The length of hospital stay since operation was also longer in older patients ( 11.8 vs. 13.1 days, $\mathrm{p} \leq 0.006)($ Tab. 3).

\section{Discussion}

The elderly patients have been recognized as high-risk candidates for open-heart procedures since the beginnings of routine cardiac surgery $(4,7,9,11,14)$. Nevertheless, due to continuous refinement of operative techniques, optimization of the cardio-pulmonary bypass and sophistication of the postoperative care cardiac surgery showed out to be feasible even in patients of a very advanced age $(1,10)$. The accumulating surgical experience has reflected in a changing attitude towards the elderly candidates of heart surgery in general and also resulted in a shift of opinion on
Tab. 1: Clinical characteristics of the patients.

\begin{tabular}{|l|c|c|c|}
\hline & Group I & Group II (70+) & \\
\hline BSA & $1.94 \pm 0.16$ & $1.86 \pm 0.16$ & $\mathrm{p} \leq 0.001$ \\
\hline BMI & $27.5 \pm 3.1$ & $26.4 \pm 3.2$ & $\mathrm{p} \leq 0.001$ \\
\hline Diabetes mellitus & $27.4 \%$ & $41.7 \%$ & $\mathrm{p} \leq 0.005$ \\
\hline Renal dysfunction & $10.8 \%$ & $19.0 \%$ & $\mathrm{p} \leq 0.005$ \\
\hline $\begin{array}{l}\text { Plasma creatinine } \\
\text { level ( } \mu \text { mol/1) }\end{array}$ & $90.5 \pm 31.7$ & $99.1 \pm 26.5$ & $\mathrm{p}=0.006$ \\
\hline $\begin{array}{l}\text { Peripheral vascular } \\
\text { disease }\end{array}$ & $14.2 \%$ & $20.5 \%$ & $\mathrm{p}=0.027$ \\
\hline $\begin{array}{l}\text { Current tobacco } \\
\text { abuse }\end{array}$ & $21.2 \%$ & $8.6 \%$ & $\mathrm{p} \leq 0.005$ \\
\hline $\begin{array}{l}\text { History } \\
\text { of TIA/stroke }\end{array}$ & $4.9 \%$ & $7.9 \%$ & $\mathrm{NS}$ \\
\hline Hypertension & $69.3 \%$ & $75.5 \%$ & $\mathrm{NS}$ \\
\hline Previous MI & $4.4 \%$ & $2.6 \%$ & $\mathrm{NS}$ \\
\hline $\begin{array}{l}\text { Previous cardiac } \\
\text { surgery }\end{array}$ & $9.7 \%$ & $12.6 \%$ & NS \\
\hline $\begin{array}{l}\text { Previous cardio- } \\
\text { logical intervention }\end{array}$ & $8.5 \%$ & $8.6 \%$ & $\mathrm{NS}$ \\
\hline COPD & $57.5 \pm 14.0 \%$ & $56.4 \pm 14.6 \%$ & $\mathrm{NS}$ \\
\hline Ejection fraction & $55.1 / 32.6 \%$ & $53.0 / 33.8 \%$ & NS \\
\hline $\begin{array}{l}\text { Hypercholesterol- } \\
\text { aemia (over 5,2 / } \\
\text { over 7,7 mmol/1) }\end{array}$ & 5.8 & $\mathrm{NS}$ \\
\hline
\end{tabular}

Tab. 2: Operative details.

\begin{tabular}{|l|c|c|c|}
\hline & Group I & Group II (70+) & \\
\hline $\begin{array}{l}\text { Non-elective } \\
\text { operation }\end{array}$ & $38.3 \%$ & $61.6 \%$ & $\mathrm{p} \leq 0.005$ \\
\hline $\begin{array}{l}\text { Number of distal } \\
\text { anastomoses }\end{array}$ & $2.6 \pm 0.9$ & $2.6 \pm 0.8$ & $\mathrm{NS}$ \\
\hline $\begin{array}{l}\text { Aortic cross-clamp } \\
\text { time (min) }\end{array}$ & $44.7 \pm 15.7$ & $44.6 \pm 16.5$ & $\mathrm{NS}$ \\
\hline $\begin{array}{l}\text { Length of CPB } \\
\text { (min) }\end{array}$ & $73.8 \pm 30$ & $81.3 \pm 35$ & $\mathrm{p} \leq 0.05$ \\
\hline $\begin{array}{l}\text { IABP - after } \\
\text { weaning off CPB }\end{array}$ & $2 \%$ & $2.6 \%$ & $\mathrm{NS}$ \\
\hline $\begin{array}{l}\text { Total blood loss } \\
\text { (ml) }\end{array}$ & $1031 \pm 787$ & $1055 \pm 853$ & $\mathrm{NS}$ \\
\hline $\begin{array}{l}\text { Transfusions of } \\
\text { PRC (units) }\end{array}$ & $2.16 \pm 2.5$ & $3.25 \pm 2.8$ & $\mathrm{p}=0.001$ \\
\hline $\begin{array}{l}\text { Length of intubation } \\
\text { (hours; median) }\end{array}$ & 17 & 20 & $\mathrm{NS}$ \\
\hline
\end{tabular}

Tab. 3: Operative mortality and postoperative course.

\begin{tabular}{|l|c|c|l|}
\hline & Group I & Group II (70+) & \\
\hline 30-days mortality & $2.3 \%$ & $7.3 \%$ & $\mathrm{p} \leq 0.005$ \\
\hline NearMiss + & $18.4 \%$ & $36.4 \%$ & $\mathrm{p}=0.005$ \\
\hline $\begin{array}{l}\text { Postoperative } \\
\text { complications }\end{array}$ & $34.6 \%$ & $56.3 \%$ & $\mathrm{p} \leq 0.005$ \\
\hline $\begin{array}{l}\text { Length of stay } \\
\text { in ICU (hours) }\end{array}$ & $56.3 \pm 86.4$ & $66.0 \pm 48.5$ & $\mathrm{p}=0.037$ \\
\hline $\begin{array}{l}\text { Length of hospital } \\
\text { stay (days) }\end{array}$ & $11.8 \pm 5.4$ & $13.1 \pm 6.4$ & $\mathrm{p}=0.006$ \\
\hline
\end{tabular}


which age exactly presents a threshold of substantially higher risk. Moreover, the cardiac surgeons from all the developed countries have been faced with an increasing demand for cardiac surgery in elderly caused by overall ageing of their populations. This demographic phenomenon caused both by prolongation of lifespan as well as reduced natality in the developed countries will bring unforseen changes in medical, social and economic aspects in oncoming decades.

Coronary revascularization for ischaemic heart disease is the most frequent type of cardiac surgery due to the prevalence of atherosclerosis in developed countries. Identification of risk-stratified groups of patients and construction of predictive models for various patients subsets have become increasingly important with regard both to the individual's risk/benefit ratio and to the cost-effectiveness in general.

Several authors analysed their results of coronary revascularization in patients of older age throughout the three recent decades $(8,13)$. In a chronological review of main papers dealing with this topic there is clearly evident that the results of CABG have been constantly improving in the course of time (Tab. 4). Similar improvement can be traced in the older groups of patients as well as cumulating experience with $\mathrm{CABG}$ in octogenarians and nonagenarians. Despite these positive trends the operative mortality in patients over 70 years still remains considerably higher than in younger groups and the mortality in patients over 80 levels up to $10-12 \%$.

Tab. 4: Outcomes of CABG in the elderly: review of cohort studies in the literature.

\begin{tabular}{|c|c|c|c|c|c|}
\hline \multirow[b]{2}{*}{ Author } & \multirow[b]{2}{*}{$\begin{array}{c}\text { Year of } \\
\text { publ. }\end{array}$} & \multicolumn{4}{|c|}{ 30-days mortality (\%) } \\
\hline & & \begin{tabular}{|c} 
Patients \\
aged \\
under 70
\end{tabular} & over 70 & over 75 & over 80 \\
\hline Gann & 1977 & & 6.7 & & \\
\hline Knapp & 1981 & 1.1 & 1.6 & & \\
\hline Gersh & 1983 & 4.6 & 6.6 & 9.5 & \\
\hline Hibler & 1983 & 4.6 & 5.0 & 20.0 & \\
\hline Hochberg & 1984 & 4.0 & 12.0 & & \\
\hline Horneffer & 1987 & 2.2 & 9.3 & & \\
\hline Goldman & 1988 & 2.9 & 6.2 & & \\
\hline Horvath & 1990 & & & 10.8 & \\
\hline Freeman & 1991 & & & & 12.9 \\
\hline Ko & 1991 & & & & 12.0 \\
\hline Tsai & 1991 & & & & 7.0 \\
\hline Hannan & 1994 & & & & \\
\hline Curtis & 1994 & & 5.2 & & \\
\hline $\mathrm{He}$ & 1994 & & 8.9 & & \\
\hline Katz & 1995 & & 6.4 & & \\
\hline Morris & 1996 & & & & 7.8 \\
\hline MEDICARE & 1995 & & & & 11.5 \\
\hline $\mathrm{KCH}$ - unit HK & 2000 & & $5.9 *$ & & \\
\hline
\end{tabular}

* - overall mortality of isolated CABG in $70+$ patients in years 1995-2000 at our unit
Most of the published papers study the population of highly developed western countries - mainly US, UK or Japan - and a limited knowledge is available about the outcome of CABG in elderly patients in Czech Republic $(2,3)$. Set for many decades in a different socio-economic situation and with its elderly patients influenced by different lifestyle patterns - resulting in high cardiovascular morbidity and mortality - there is an obvious need for comparison of results and risk stratification in this specific subset of population. In our study we performed retrospective analysis of isolated $\mathrm{CABG}$ procedures with respect to age in a consecutive series of our patients; this cohort will then be a subject to further longitudinal follow-up.

What are the recognized risk factors of elderly candidates of CABG? In a clear presumption of worse outcomes of surgery in these patients we in no way can be surprised by a presence of important risk factors: higher stage of NYHA and CCS, diabetes, manifestations of extracardiac obliterative arteriosclerosis, renal dysfunction. The advanced stage of cardiac disease is principally caused by its longer duration and partly also by previous postponement of radical treatment in otherwise risky patients - this is globally expressed in a higher percentage of urgent, non-elective CABG procedures. The prevalence of diabetes was significantly higher in elderly in our study and this comorbidity presents an important potential for multiple negative effects - advanced morphologic changes in coronary arteries, renal dysfunction or impaired wound healing. With regard to the age of CABG candidates the presence of diabetes displays a bell-shaped relation - while markedly more frequent in septuagenarians it again decreases in octogenarians and older patients to values of middle-age populations (9). This phenomenon is probably caused by a careful selection of octogenarians for CABG treatment as well as a reduced life span in diabetic patients.

A higher percentage of stenotic carotid lesions is well documented in our study due to routine Doppler ultrasound examination, which was part of our standard preoperative protocol in these years. Though the preoperative history of transient cerebral ischaemia or stroke was not statistically different between group I and II ( 5 vs. $8 \%$ ) the presence of advanced atherosclerosis both in extracranial and intracranial vessels is no doubt a major contributing factor for significantly higher incidence of postoperative neurological and neuropsychical disorders in group II.

The elderly patients in our study had significantly lower BSA and BMI. The exact explanation of this finding remains uneasy since several possible effects can play role simultaneously. On one hand, we can speculate that higher BMI in younger patients may be an expression of pro-atherogenic nutritional/metabolic disorder, on the other hand smaller BSA found in elderly is a known risk factor of poor operative results mainly on basis of small vessel diameter in general.

The renal dysfunction is another potent threat jeopardizing the outcome of surgery in elderly. A higher incidence 
of impaired renal function in patients' history and a higher entry serum creatinine level is well documented in the group II. The pre-existing diminished renal capacity together with adverse effects of low-cardiac output which was also more frequent in the elderly group set the ground for significantly higher occurrence of postoperative renal disorders in the older group (12).

Based upon a cluster of known risk factors there is no surprize that the 30-days mortality of our sample of elderly Czech CABG population is significantly different from that of the younger patients (2.3 vs. $7.3 \%, \mathrm{p} \leq 0.005$ ). Similarly, the incidence of NearMiss + is again two-fold higher in the elderly group. These findings are in a good correlation with the results in western population. Thus, with respect to no noticeable differences in operative strategy or technique (with exception of the duration of cardio-pulmonary bypass which was slightly longer in the elderly group), the worse results seem to be attributable to higher preoperative comorbidity and age-related diminished functional capacity of the septuagenarians. The overall fragility of these patients is clearly displayed in a wide spectrum of postoperative complications all of them being more frequent in the elderly. The most pronounced are the renal and respiratory failure, neurological and neuropsychical disorders, low cardiac output and arrhytmias.

\section{Conclusion}

Hereby accumulated evidence supports the thesis that the older age of the candidates of CABG is a messenger of elevated risks and worse results of the surgery due to higher pre-operative co-morbidity and overall decreased vital capacity. This phenomenon per se keeps unaffected by the continuous refinement of operative techniques and accumulation of knowledge in cardiac surgery.

On the contrary, also important positive aspects are inherent in the topic despite unanimously worse trends. Though risky, the coronary revascularization in older age groups has remained an attractive challenge for cardiac surgeons throughout the decades and, moreover, even the patients of a very advanced age are now considered suitable candidates for $\mathrm{CABG}$.

In fact, the proportion of elderly patients in coronary surgery has been raising strikingly and this is not merely a reflection of the demographic ageing, but also the expression of an active surgical approach. The coronary surgery has been offered to the elderly increasingly even though their treatment burdens the health institutions with longer ICU/in-hospital stays and extra costs. The surgical coronary revascularization in the older groups has been able to stand the competition with interventional cardiological procedures (the beneficial effects of which showed out to be less durable than in younger groups). The continuous effort for optimization, which succeeded in transforming $\mathrm{CABG}$ in a standard low-risk procedure in general, has brought also a dramatic reduction of mortality/morbi- dity of CABG in the elderly population. Nevertheless, except for a few reports of excellent results the large statistics display less favourable early results in septuagenarians and older age groups. The impact of newly introduced off-pump revascularization techniques still needs to be evaluated carefully. In the opinion of the author, the potential benefits of this type of treatment in elderly may be weakened by incremental risks mainly due to technical problems in vessels with advanced arteriosclerosis.

The long-term results and quality of life after the surgery are the indispensable factors in evaluating the outcome of the operation. Several investigators examined the postoperative quality of life in elderly by means of structured questionnaires and proved that not only the life-expectancy of elderly CABG survivors is equivalent to age-matched non diseased population but that these patients enjoy a good satisfaction from the cardiac operation and perceive improved well-being in physical functioning as well as in scores of mental health $(13,14)$. The patients of our study will be subject to a similar mid-term follow-up survey.

Coronary revascularization in elderly patients is fully justified rational treatment. In the light of the late benefits even somewhat higher operative mortality/morbidity seems acceptable. However, prudent weighing of individual risks still remains to be the critical issue in adjusting the proper strategy of treatment of coronary heart disease in elderly patients.

\section{References}

1. Alexander KP, Anstrom KJ, Muhlbaier LH et al. Outcomes of cardiac surgery in patients > or $=80$ years: results from the National Cardiovascular Network. J Am Coll Cardiol 2000;35(3):731-8.

2. Čoček D., Pirk J., Šetina M., Mokráček A. Srdeční operace u pacientů nad 75 let. Cor Vasa 2001;43(4):179-83.

3. Frélich M., Štětka F., Němec P., Wagner R., Šimková M., Šimek P. Naše zkušenosti s chirurgickou revaskularizaci myokardu u 70letých a starších nemocných. Cor Vasa 2001;43(1):28-32

4. Gann D, Colin C, Hildner FJ, Samet P, Yahr WZ, Greenberg JJ. Coronary artery bypass surgery in patients seventy years of age and older. Journal of Thoracic and Cardiovascular Surgery 1977;73(2):237-41.

5. Glower DD, Christopher TD, Milano CA et al. Performance status and outcome after coronary artery bypass grafting in persons aged 80 to 93 years. Am J Cardiol 1992;70(6):567-71.

6. Heijmeriks JA, Pourrier S, Dassen P, Prenger K, Wellens HJ. Comparison of quality of life after coronary and/or valvular cardiac surgery in patients $>$ or $=75$ years of age with younger patients. Am J Cardiol 1999;83(7):1129.

7. Horvath KA, DiSesa VJ, Peigh PS, Couper GS, Collins JJJ, Cohn LH. Favorable results of coronary artery bypass grafting in patients older than 75 years [see comments]. J Thorac Cardiovasc Surg 1990;99(1):92-6.

8. Ivanov J, Weisel RD, David TE, Naylor CD. Fifteen-year trends in risk severity and operative mortality in elderly patients undergoing coronary artery bypass graft surgery. Circulation 1998;97(7):673-80.

9. Khan SS, Kupfer JM, Matloff JM, Tsai TP, Nessim S. Interaction of age and preoperative risk factors in predicting operative mortality for coronary bypass surgery. Circulation 1992;86(Suppl 5):II186-II190.

10. Kirsch M, Guesnier L, LeBesnerais $P$ et al. Cardiac operations in octogenarians: perioperative risk factors for death and impaired autonomy. Ann Thorac Surg 1998;66(1):60-7.

11. Knapp WS, Douglas JSJ, Craver JM et al. Efficacy of coronary artery bypass grafting in elderly patients with coronary artery disease. Am J Cardiol 1981:47(4):923-30

12. Longo KM, Cowen ME, Flaum MA et al. Preoperative predictors of cost in Medicare-age patients undergoing coronary artery bypass grafting. Annals of Thoracic Surgery 1998;66:740-5. 
13. Peterson ED, Cowper PA, Jollis JG et al. Outcomes of coronary artery bypass graft surgery in 24,461 patients aged 80 years or older. Circulation 1995;92(Suppl 9):II85-II91.

14. Smith JM, Lindsay W.G., Lillehei RC, Nicoloff DM. Cardiac surgery in geriatric patients. Surgery 1976;80(4):443-8

Submitted June 2001.

Accepted November 2001.

MUDr. Pavel Žáček,

Charles University in Prague, Faculty of Medicine in Hradec Králové, Department of Cardiac Surgery, 50005 Hradec Králové, Czech Republic. e-mail: zacek@fnhk.cz 